American Journal of Pharmacology and Toxicology 2 (3): 106-110, 2007

ISSN: $1557-4962$

(C) 2007 Science Publications

\title{
Anti-hyperglycaemic and Anti-obesity Effects of Capparis spinosa and Chamaemelum nobile Aqueous Extracts in HFD Mice
}

\author{
${ }^{1}$ A. Lemhadri, ${ }^{1}$ Mohamed Eddouks, ${ }^{3}$ Thierry Sulpice and ${ }^{2}$ Remy Burcelin \\ ${ }^{1}$ UFR PNPE, BP.21, Errachidia, 52000, Morocco \\ ${ }^{2}$ UMR 5018 CNRS-UPS and IFR 31, Rangueil Hospital, Toulouse, France \\ ${ }^{3}$ Physiogenex, Toulouse, France
}

\begin{abstract}
This study was undertaken in order to evaluate the possible anti-hyperglycaemic and body weight reducing activities of the aqueous extract of both Capparis spinosa (CS) and Chamaemelum nobile $(\mathrm{CN})\left(20 \mathrm{mg} \mathrm{kg}^{-1}\right)$. The results demonstrate clearly that repeated oral administration of both CS and $\mathrm{CN}$ aqueous extract evoked a potent anti-hyperglycaemic activity in high fat diet (HFD) obese mice. Postprandial hyperglycaemic peaks were significantly lower in plant-treated experimental groups. In other hand, body weight was significantly lower in CS and CN-treated groups when compared to the control one after daily oral administration of CS and $\mathrm{CN}$ aqueous extracts for 15 days. We can conclude that these plants evoked potent anti-hyperglycaemic and anti-obesity effects. This fact could support their use by the Moroccan population for diabetes control and treatment.
\end{abstract}

Key words: High fat diet, obesity, oral administration, body weight, mice

\section{INTRODUCTION}

Diabetes mellitus is a metabolic disease characterized by hyperglycaemia resulting from defects in insulin secretion, insulin action, or both ${ }^{[1]}$. Diabetes mellitus takes two major forms; type 1 and type 2 diabetes mellitus. Although the two types of diabetes have distinct pathogenesis, hyperglycemia, insulin resistance and various hyperglycemia-related complications are the most common features.

Prior to the discovery of insulin and other hypoglycaemic synthetic drugs, herbal medicine has been long used for the treatment of diabetic patients and they are currently accepted as an alternative therapy for diabetic treatment and control. Recent scientific investigation and clinical studies have confirmed the efficacy of many medicinal plants and herbal preparations in the improvement of normal glucose homeostasis. Capparis spinosa L. (CS) (Capparidaceae) and Chamaemlum nobile (CN) (Asterceae) were reported to have a number of potentially useful medicinal attributes including anti-oxidative ${ }^{[2]}$, antifungal $^{[3]}$, antihepatotoxic ${ }^{[4]}$, anti-inflammatory ${ }^{[5,6]}$ and anti-diabetic ${ }^{[7]}$. In Morocco, these plants were traditionally used in diabetes control and treatment ${ }^{[8-10]}$. Previously, we have reported the hypoglycaemic activity of the aqueous extract of CS fruits and $\mathrm{CN}$ aerial parts in streptozotocin-induced diabetic rats, an animal model of human type 1 diabetes mellitus ${ }^{[11,12]}$. Therefore, the aim of the present study was to investigate the potential hypoglycaemic and body weight reducing activities of Capparis spinosa and Chamaemelun nobile aqueous extracts in an animal model with type 2 diabetes. We have used the HFD mouse model, which exhibits profound obesity and insulin resistance ${ }^{[13]}$. In HFD mice, feeding of a hypercaloric diet leads to obesity and metabolic abnormalities, such as hyperglycemia, glucose intolerance and hyperinsulinemia, that phenotypically resemble human type 2 diabetes.

\section{MATERIALS AND METHODS}

Plant material: Specimens of Capparis spinosa (Capparidaceae) and Chamaemelum nobile (Asteraceae) were collected from the Tafilalet region (semi-arid area) of Morocco in May-June 2004 and airdried at $40^{\circ} \mathrm{C}$. These plants were previously identified and authenticated by Pr. M. Rejdali (Agronomy and Veterinary Institute, Rabat) and a voucher specimen (ME 35 and ME 60) Eddouks et al. ${ }^{[10]}$ was deposited at the herbarium of the Faculty of Sciences and Techniques Errachidia.

Preparation of the aqueous extract: Plant material was prepared according to the traditional method used

Corresponding Author: Prof Mohamed EDDOUKS. UFR PNPE, BP.21, Errachidia, 52000, Morocco Tel: +212 35574497 Fax: +21235 574485 
in Morocco (decoction): $1 \mathrm{~g}$ of powdered fruits mixed with $100 \mathrm{ml}$ distilled water were boiled for 10 minutes and then cooled for 15 minutes. Thereafter, the aqueous extract was filtered using a Millipore filter (Millipore $0.2 \mathrm{~mm}$, St Quentin en Yvelines, France) to remove particulate matter. The filtrate was then freeze-dried and the desired dose (mg of lyophilized aqueous extract of plant per kg body weight) was then prepared and reconstituted in $1.5 \mathrm{ml}$ of distilled water. The extracts obtained were then given orally to different groups of mice at a dose of $20 \mathrm{mg} \mathrm{kg}^{-1}$ body weight. The dose of $20 \mathrm{mg} \mathrm{kg}^{-1}$ was used according to the Moroccan traditional phytotherapy.

Experimental animals: Eleven-week-old male C57BL/6J mice (Janvier, Le Genest Saint Isle, France) were housed in a controlled environment (inverted 12-h daylight cycle, lights off at 10:00 a.m.) with free access to food and water in groups of five mice per cage at $22^{\circ} \mathrm{C}$. All animal experimental procedures have been approved by the local ethical committee of the Rangueil hospital.

Induction of glucose intolerance: Glucose intolerance was induced in male C57BL/6J mice by feeding a highfat diet (UAR, Epinay sur Orge, France) for 28 days. The energy content was $72 \%$ fat (corn oil and lard), $28 \%$ protein and $1 \%$ carbohydrates.

Acute and chronic oral treatment: Normal and diabetic mice were randomly assigned to two groups ( $\mathrm{n}=10$ in each group). The control group received distilled water and the treated-group received aqueous extract of $\mathrm{CN}$ or CS at a dose of $20 \mathrm{mg} \mathrm{kg}^{-1} \mathrm{~B}$.W. The $\mathrm{CN}$ or $\mathrm{CS}$ aqueous extracts and vehicle were administered orally by gastric intubation using a syringe once daily at $10 \mathrm{~h}$ a.m.

Intraperitoneal glucose tolerance test: An intraperitoneal glucose tolerance test was performed three weeks after the beginning of the feeding period. Six-hour-fasted mice received an intraperitoneal injection of glucose $\left(1 \mathrm{~g} \mathrm{~kg}^{-1}\right.$ body wt). Blood glucose was determined with a glucose meter (Roche Diagnostic) on $3.5 \mu \mathrm{L}$ of blood collected from the tip of the tail vein, $30 \mathrm{~min}$ before and $0,15,30,60,90$ and $120 \mathrm{~min}$ following glucose injection. Blood glucose levels were determined by glucose oxidase method using a reflective glucometer.

Statistical analysis: All the data reported are expressed as mean \pm S.E.M. Statistical analysis was performed using the Student's t-test. The values were considered to be significantly different when the P-value was less than 0.05 compared to baseline or control values.

\section{RESULTS}

Single oral administration: The effects of single oral administration of the aqueous extract of CS fruits and $\mathrm{CN}$ aerial parts at a dose of $20 \mathrm{mg} \mathrm{kg}^{-1}$ B.W. on glucose intolerance test are shown in Fig. 1. Blood glucose levels did not change significantly between the start and the end of treatment in the CS and CN treated groups (Fig. 1). However, in the control group receiving distilled water, the blood glucose levels remain significantly higher when compared to starting value $(\mathrm{p}<0.05)$.

No significant difference was noted in both control and CS-treated groups (Table 1). However, in CNtreated group, AUC were significantly lower when compared to control values $(425.00 \pm 20.08$ vs $\left.478.83 \pm 21.20 \mu \mathrm{M} \mathrm{min}^{-1} ; \mathrm{p}<0.05\right)$.

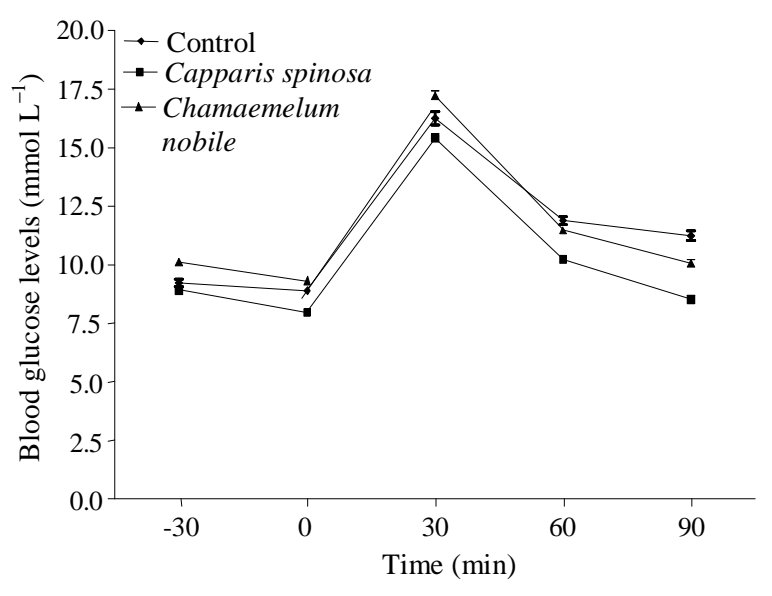

Fig 1: Intraperitoneal glucose tolerance test after single oral administration of the aqueous extracts of Capparis spinosa and Chamaemelum nobile (20 $\mathrm{mg} \mathrm{kg}^{-1}$ B.W.). For each group, $\mathrm{n}=10$

Table 1: Values of Area Under Curve (AUC) $\left(\mu \mathrm{M} \mathrm{min}{ }^{-1}\right)$

\begin{tabular}{|c|c|c|c|}
\hline \multirow{2}{*}{$\begin{array}{l}\text { Experimental } \\
\text { groups }\end{array}$} & \multicolumn{3}{|c|}{ Area under curve $\left(\mu \mathrm{M} \min ^{-1}\right)$} \\
\hline & $0-90 \mathrm{~min}$ & $60-90 \mathrm{~min}$ & $-30-90 \mathrm{~min}$ \\
\hline Control & $57.46 \pm 0.59$ & $23.11 \pm 1.09$ & $478.83 \pm 21.20$ \\
\hline $\begin{array}{l}\text { Capparis } \\
\text { spinosa }\end{array}$ & $58.11 \pm 1.94^{\mathrm{NS}}$ & $21.50 \pm 0.81^{\mathrm{NS}}$ & $484.25 \pm 16.19^{\mathrm{NS}}$ \\
\hline $\begin{array}{l}\text { Chamaemelum } \\
\text { Nobile }\end{array}$ & $51.00 \pm 2.41 *$ & $18.73 \pm 1.07 *$ & $425.00 \pm 20.08 *$ \\
\hline
\end{tabular}


Am. J. Pharm. \& Toxicol., 2 (3): 106-110, 2007

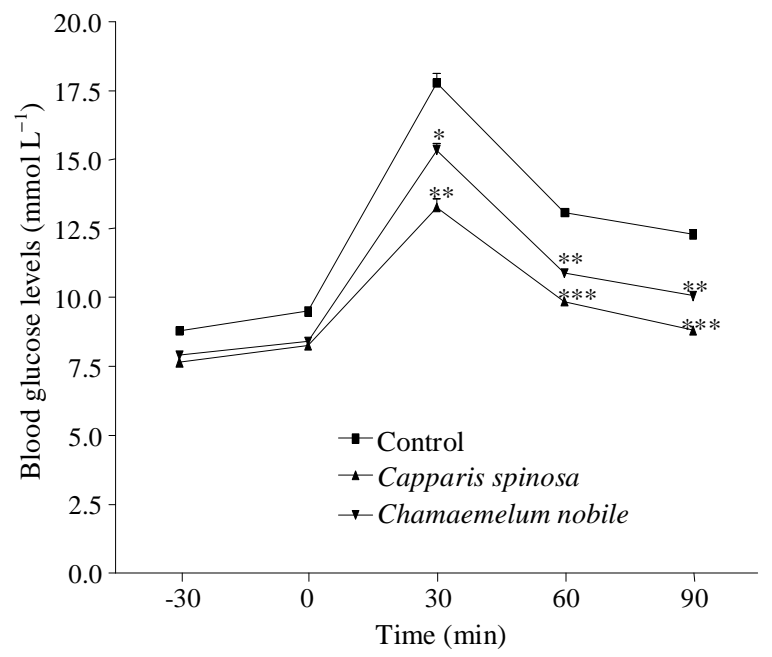

Fig. 2: Intraperitoneal glucose tolerance test after repeated oral administration for 15 days of the aqueous extracts of Capparis spinosa and Chamaemelum nobile (20 mg kg ${ }^{1}$ B.W.). *: $\mathrm{p}<0.05 ; \quad * *: \quad \mathrm{p}<0.01 ; \quad * * *: \quad \mathrm{p}<0.001$ when compared to baseline values. For each group, $\mathrm{n}=10$

Table 2: Area Under Curve (AUC) $\left(\mu \mathrm{M} \mathrm{min}{ }^{-1}\right)$ of intraperitoneal glucose tolerance test after single oral administration of the aqueous extracts of Capparis spinosa and Chamaemelum nobile (20 mg kg $\mathrm{mg}^{-1}$ B.W). For each group, $\mathrm{n}=10$

\begin{tabular}{|c|c|c|c|}
\hline \multirow{2}{*}{$\begin{array}{l}\text { Experimental } \\
\text { groups }\end{array}$} & \multicolumn{3}{|c|}{ Area under curve $\left(\mu \mathrm{M} \mathrm{min}{ }^{-1}\right)$} \\
\hline & $0-90 \mathrm{~min}$ & $60-90 \mathrm{~min}$ & $-30-90 \mathrm{~min}$ \\
\hline Control & $61.50 \pm 1,68$ & $25.36 \pm 0.91$ & $512.50 \pm 14.02$ \\
\hline $\begin{array}{l}\text { Capparis } \\
\text { spinosa }\end{array}$ & $52.59 \pm 1,48^{*}$ & $20.93 \pm 0.7 *$ & $438.25 \pm 12.40^{* *}$ \\
\hline $\begin{array}{l}\text { Chamaemelum } \\
\text { nobile }\end{array}$ & $47.81 \pm 2,39 * *$ & $18.65 \pm 0.8^{*}$ & $398.41 \pm 19.93^{* *}$ \\
\hline
\end{tabular}

Repeated oral administration: Figure 2 shows the effects of daily repeated oral administration of CS and $\mathrm{CN}$ aqueous extracts (20 mg kg${ }^{-1}$ B.W.) for two weeks on glucose intolerance in obese mice. Hyperglycaemic peaks obtained at 30 min were significantly lower in CS $(\mathrm{p}<0.001)$ and $\mathrm{CN}(\mathrm{p}<0.01)$ treated groups than in water distilled treated groups (Fig. 2).

Values of AUC after repeated oral administration of the aqueous extracts of these plants were summarized in Table 2. A strong reduction in AUC was observed after plants treatment. AUC were 22 and $15 \%$ lower in CS and CN treated group respectively than in control groups $(398.41 \pm 19.93$ and $438.25 \pm 12.40$ vs $\left.512.50 \pm 14.02 \mu \mathrm{M} \mathrm{min}^{-1} ; \mathrm{p}<0.001\right)$.

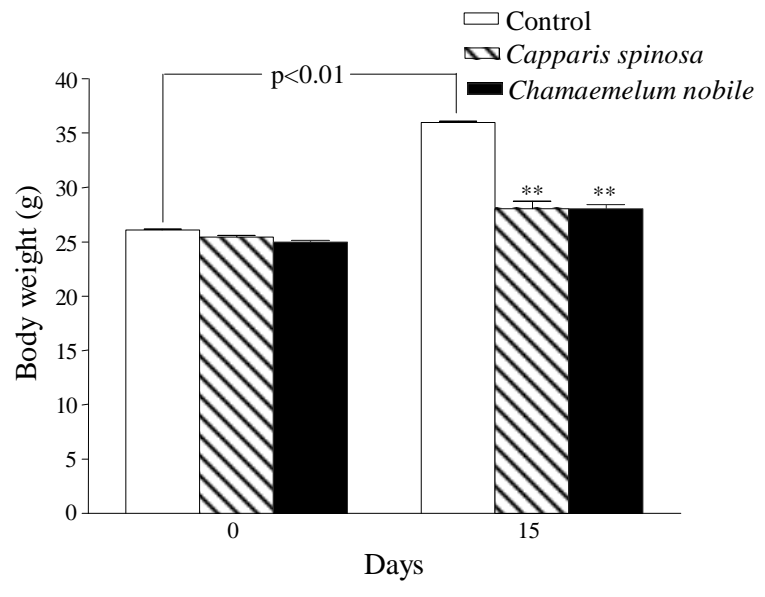

Fig. 3: Effect of Capparis spinosa and Chamaemelum nobile treatment $\left(20 \mathrm{mg} \mathrm{kg}^{-1}\right.$ B.W.) for 15 days on body weight ( $\mathrm{g}$ ) in HFD mice. **: $\mathrm{p}<0.01$ when compared to baseline values. For each group, $\mathrm{n}=10$

Body weight: Time course evolution of body weight is shonw in Fig. 3. A significant increase in body weight was observed in the control group from the first day to the 15th day $(\mathrm{p}<0.01)$ (Fig. 3). While, no significant difference in body weight was noted in experimental groups treated with both $\mathrm{CS}$ and $\mathrm{CN}$ aqueous extracts between D0 and D15 (Fig. 3). However, at the end of the treatment, body weight values were significantly lower in $\mathrm{CS}$ and $\mathrm{CN}$-treated groups when compared to the control groups ( $\mathrm{p}<0.01)$ (Fig. 3).

\section{DISCUSSION}

The present study was carried out in order to investigate the hypoglycaemic and body weight reducing activities of the aqueous extract of both Capparis spinosa and Chamaemelum nobile in high fat diet (HFD) mice. This animal model is considered as the adequate model for studying pathophysiology of human type 2 diabetes. In this animal model, development of glucose intolerance and diabetes are tightly associated with genetic predisposition and environmental factors ${ }^{[14]}$.

Our results clearly demonstrate that repeated oral administration of aqueous CS and CN extracts for two weeks was accompanied by an important improvement in glucose tolerance and a strong decrease of body weight in highly glucose intolerant HFD mice. This finding is in concordance with our previous work which has demonstrated a potent hypoglycaemic activity in streptozotocin-induced diabetic rats $^{[11,12]}$. Several 
metabolic abnormalities have been reported to be associated with the development of glucose intolerance and diabetes in HFD mice. These abnormalities include; decrease in glucose transport and oxidation rate, decrease in glycogen synthesis ${ }^{[15]}$. The results obtained in this study clearly demonstrate that both $\mathrm{CS}$ and $\mathrm{CN}$ treatment were associated with a potent improvement of glucose intolerance. The AUC values were 22 and $15 \%$ lower in the group treated with $\mathrm{CN}$ and CS respectively. Since obesity is often accompanied by insulin resistance. The mechanism underlying the reported therapeutic activity may involve, at least, an improvement of insulin sensitivity which can lead to an increase in peripheral glucose utilization ${ }^{[16-18]}$. Scientific records reveal that plants such Panax ginseng ${ }^{[19,20]}$, Acanthopanax senticosus ${ }^{[21]}$, Salix matsudana ${ }^{[22]}$ have been reported to posses insulin sensitizing activities in nutrition induced obese animals. A similar mechanism may operate in the plant extracts-treated HFD mice to improve glucose homeostasis. Another possible action site for $\mathrm{CN}$ and $\mathrm{CS}$ to exert its postprandial hypoglycemic effect is in the gastrointestinal tract. These plants may slow the digestion of food and decrease the rate of carbohydrate absorption and clearing the postprandial glucose load.

Obesity is associated with insulin resistance and cardiovascular diseases risk factors ${ }^{[17]}$. Thus, insulin resistance in obese type 2 diabetic patients is significantly worse than that in nonobese diabetic individuals ${ }^{[23]}$. Therapeutic agents with both antidiabetic and anti-obese effects are therefore particularly beneficial. Our results show that HFD mice treated with Capparis spinosa and Chamaemelun nobile extracts underwent a time-dependent reduction in body weight. Previous studies have shown that insulin sensitivity in type 2 diabetic patients improves with weight $\operatorname{loss}^{[24]}$, possibly because of an improvement in insulin-stimulated glucose transport into muscle ${ }^{[18]}$. A similar mechanism may operate in the extract-treated HFD mice to improve glucose homeostasis.

In conclusion, the aqueous extracts of both plants exhibits potent antihyperglycaemic and anti-obesity effects. These plants may exert their antidiabetic and anti-obesity effects through actions that improve insulin sensitivity and the balance between food intake and energy expenditure.

\section{REFERENCES}

1. The Expert Committee on the Diagnosis and Classification of Diabetes Mellitus, 2002. Report of the expert committee on the diagnosis and classification of diabetes mellitus. Diabetes Care, 25: S5-S15.
2. Germano, M.P., R. De Pasquale, V. D'Angelo, S. Catania, V. Silvari and C. Costa, 2002. Evalution of extracts and isolated fraction from Capparis spinosa L. buds as antioxidant source. J. Agric. Food Chem., 50: 1168-1171.

3. Ali-Shtayeh, M.S. and S.I. Abu-Ghdeib, 1999. Antifungal activity of plant extracts against dermatophytes. Mycoses, 42: 665-672.

4. Gadgoli, C. and S.H. Mishra, 1999. Antihepatotoxic activity of p-methoxy benzoic acid from Capparis spinosa. J. Ethnopharmacol., 66: 187-192.

5. Al-Said, M.S., E.A. Abdelsattar, S.I. Khalifa and F.S. El-Feraly, 1988. Isolation and identification of an anti-inflammatory principle from Capparis spinosa. Pharmazie, 43: 640-641.

6. Rossi, T., M. Melegari, A. Bianchi, A. Albasini and G. Vampa, 1988. Sedative, anti-inflammatory and anti-diuretic effects induced in rats by essential oils of varieties of Anthemis nobilis: A comparative study. Pharm. Res. Commun., 20: 71-74.

7. Yaniv, Z., A. Dafni, J. Friedman and D. Palevitch, 1987. Plants used for the treatment of diabetes in Israel. J. Ethnopharmacol., 2: 145-151.

8. Ziyyat, A., H. Legssyer, A. Mekhfi, M. Dassouli, M. Serhrouchni and W. Benjelloun, 1997. Phytotherapy of hypertension and diabetes in Oriental Morocco. J. Ethnopharmacol., 58: 45-54.

9. Jouad, H., M. Haloui, H. Rhiouani, J. El Hilaly and M. Eddouks, 2001. Ethnobotanical survey of medicinal plants used for the treatment of diabetes, cardiac and renal diseases in the North centre region of Morocco (Fez-Boulemane). J. Ethnopharmacol., 77: 175-182.

10. Eddouks, M., M. Maghrani, A. Lemhadri, M.L. Ouahidi and H. Jouad, 2002. Ethnopharmacological survey of medicinal plants used for the treatment of diabetes mellitus, hypertension and cardiac diseases in the south-east region of Morocco (Tafilalet). J. Ethnopharmacol., 82: 97-103.

11. Eddouks, M., A. Lemhadri and J.B. Michel, 2004. Caraway and caper: Potential antihyperglycaemic plants in diabetic rats. J. Ethnopharmacol., 94: 143-148.

12. Eddouks, M., A. Lemhadri, N.A. Zeggwagh and J.B. Michel, 2005. Potent hypoglycaemic activity of the aqueous extract of Chamaemelum nobile in normal and streptozotocin-induced diabetic rats. Diabetes Res. Clin. Pract., 67: 189-195. 
13. Zhang, Y., R. Proenca, M. Maffel, M. Barone, L. Leopold and J.M. Friedman, 1994. Positional cloning of the mouse obese gene and its human homologue. Nature, 372: 425-432.

14. Surwit, R.S., C.M. Kuhun, C. Cochrane, J.A. McCubbin and M.N. Feinglos, 1988. Dietinduced type II diabetes in $\mathrm{C} 57 \mathrm{BL} / 6 \mathrm{~J}$ mice. Diabetes, 37: 1163-1167.

15. Kim, J.K., J.K. Wi and J.H. Youn, 1996. Metabolic impairment precedes insulin resistance in skeletal muscle during high-fat feeding in rats. Diabetes, 5: 651-658.

16. Bavenholm, P.N., J. Pigon, C.G. Ostenson and S. Efendic, 2001. Insulin sensitivity of suppression of endogenous glucose production is the single most important determinant of glucose tolerance. Diabetes, 50: 1449-1454.

17. Kruszynska, Y.T and J.M. Olefsky, 1996. Cellular and molecular mechanisms of non-insulin dependent diabetes mellitus. J. Investig. Med., 44: 413-428.

18. Friedman, J.E., G.L. Dohm, N. Leggett-Frazier, C.W. Elton, E.B. Tapscott, W.P. Poriesand J.F Caro, 1992. Restoration in insulin responsiveness in skeletal muscle of morbidly obese patients after weight loss. J. Clin. Investig., 89: 701-705.

19. Attele, A.S., Y.P. Zhou, J.T. Xie, J.A. Wu, L. Zhang, L. Dey, W. Pugh, P.A. Rue, K.S. Plonsky and C.S. Yuan, 2002. Antidiabetic effects of Panax ginseng berry extract and the identification of an effective component. Diabetes, 51: 1851-1858.
20. Yun, S.N., S.J. Moon, S.K. Ko, B.O. Im and S.H. Chung, 2004. Wild ginseng prevents the onset of high-fat diet induced hyperglycemia and obesity in ICR mice. Arch. Pharmacol. Res., 27: 790-796.

21. Cha, Y.S., S.J. Rheeand Y.R. Heo, 2004. Acanthopanax senticosus extract prepared from cultured cells decreases adiposity and obesity indices in C57BL/6J mice fed a high fat diet. J. Med. Foods, 7: 422-429.

22. Han, L.K., M. Sumiyoshi, J. Zhang, M.X. Liu, X.F. Zhang, Y.N. Zheng, H. Okuda and Y. Kimura, 2003. Anti-obesity action of Salix matsudana leaves (Part 1). Anti-obesity action by polyphenols of Salix matsudana in high fat-diet treated rodent animals. Phytotherap. Res., 17: 1188-1194.

23. Seely, B.L. and J.M. Olefsky, 1993. Potential Cellular and Genetic Mechanisms for Insulin Resistance in Common Disorders of Obesity and Diabetes. In: Insulin Resistance and Its Clinical Disorders, Moller, D. (Ed.). Wiley, Chichester, UK., pp: 187-252.

24. DeFronzo, R.A. and E. Ferrannini, 1991. Insulin resistance: A multifaceted syndrome responsible for NIDDM, obesity, hypertension, dyslipidemia and atherosclerotic cardiovascular disease. Diabetes Care, 14: 173-194. 